International Journal of Engineering \& Technology, 7 (4) (2018) 2028-2034
International Journal of Engineering \& Technology
SPC
Website: www.sciencepubco.com/index.php/IJET
doi: $10.14419 /$ ijet. $v 74$ it.13041
Research paper

\title{
Motion control of linear induction motor based on optimal recurrent wavelet neural network-PID controller
}

\author{
Ameer L. Saleh ${ }^{1 *}$, Badiryah A. Obaid ${ }^{2}$, Adel A. Obed ${ }^{3}$ \\ ${ }^{1}$ Department of Electrical Engineering, University of Misan, Misan, Iraq \\ ${ }^{2}$ Department of Electronic Technologies, Basra Technical Institute, Southern Technical University, Basra, Iraq \\ ${ }^{3}$ Department of Electrical Engineering Technical college, Middle Technical University, Baghdad, Iraq \\ *Corresponding author E-mail: the_prince377@yahoo.com
}

\begin{abstract}
This paper contains a proposed controller based on optimal recurrent wavelet neural network (RWNN) with PID controller to control the velocity and hence the stator current as well as the developed thrust of three phase linear induction motor (LIM) which consider the end effects. A vector control represented by indirect field oriented control (IFOC) technique is appointed to attain velocity and flux control for different loading conditions. Moreover, a voltage source inverter based on space vector pulse width modulation (SVPWM) is utilized to give the required stator voltage of LIM. A well-known particle swarm optimization (PSO) algorithm is employed for online tuning of the proposed controller. The computer simulation results show that this controller is effective and gives preferable and rigorous performance compared with a results obtained from conventional wavelet neural network (WNN) and PID controllers.
\end{abstract}

Keywords: LIM; Modeling and Simulation; SVPWM Inverter; IFOC Method; RWNN; PSO Algorithm.

\section{Introduction}

Recently, linear induction motor is preferred in many industrial applications such as transport uses, belt conveyor systems, modern trains, actuators and different material handling, etc. due to its excellent performance such as wide range velocity operation, high-starting thrust force, reduction of mechanical losses and relief gear between used motor and devices movement compared with rotary induction motor [1].

LIM is derived from rotary induction motor (RIM) by its virtual cutting process and splitting. The principle of operation of LIM is comparable to the conventional (rotary) induction motor however the different is in some internal merits such as longitudinal endeffect, transversal edge-effect and normal force. The major difference between the RIM and LIM is related to the end effect which effects on the motor parameters and the operation of the motor under the normal condition and should be considered in both the modelling and controlling of LIMs. Since, the primary of LIM has a finite length with a fringing field for both ends of what primary which effect on magnetic field changes the LIM's performance. These effects must be taken into consider during entry and out from the secondary, with respect to the primary and be required them neatly to get the LIM equivalent circuit [1], [2].

LIM can be either a short primary or a short secondary and also the motor can be single-sided or a double-sided. In this paper, single-sided LIM with primary shorted and infinite secondary type taking into account the end effect is used.

Currently, several control categories have been utilized to control the velocity of the LIM. The field-orientation control is the most effective method that control the AC motor speed to get better performance. The IFOC method is used to control the velocity of LIM because the control characteristics is more complicated compare with speed control of RIM, and motor parameters are always varying under the normal running conditions due to end effect[3]. The main goal of the indirect FOC is to separate the flux and torque in a LIM which achieve by separating the primary and the secondary currents into its portions in $\mathrm{d}-\mathrm{q}$ axis reference frame system. The first portion (q-axis component) is independent of the end effects, and the second portion(d-axis component) dependent of the end effects, where the two portions are controlled by current controller to give the desired control signal to the three phase inverter with SVPWM technique. The Space Vector Modulation (SVM) was derived from Pulse Width Modulation (PWM) technique for 3-phase inverter is utilized to give good performance for the output voltages with less harmonics [4].

In the last decade, There are several control techniques utilized with intelligent control methods to control the LIM to give performance resemble the separately excited DC machines[1]-[5].

In this paper, an optimized recurrent wavelet neural network (RWNN) strategy based on indirect field oriented control (IFOC) is proposed for velocity control of the LIM considering with end effects. This controller supports the velocity and tracking flux under the uncertainties of the motor parameter and the load thrust disturbance. The proposed system consists of two schemes, velocity controller and current controller. To achieve the required speed, a velocity controller is used which includes RWNN with PID controller while the flux can be controlled based on the IFOC using two loops of $\mathrm{d}$-q axis current. For each loop, RWNN controller is used to give the required $v_{d}$ and $v_{q}$ to SVPWM inverter. The PSO algorithm is utilized for learning the parameters of the proposed controller. 


\section{Control design}

\subsection{LIM control based indirect field orientation}

The control based on field orientation techniques depend on decoupling torque and flux variables in the machine. This can achieve a performance similar to performance of separately excited DC machine.

The end effect is noticeable and effective in the LIM compared to the rotary induction motors where it is not noticeable. The dynamic model of the LIM has been represented utilizing the $\mathrm{d}-\mathrm{q}$ model and the electrical circuit of the LIM is extremely similar to the electrical circuit of the RIM but differs from it by influencing the end effect. The q-axis equivalent circuit for the LIM is same to that of a RIM because the end effects are not very observable in qaxis. Sophistically the parameters don't change with the end effect, While the end effect increases in d-axis due to the influenced air gap flux by the linor d-axis entry currents. Therefore, the similar circuit in d-axis of the RIM can't be used in the LIM analysis with considering the end effects. Figure. 1 shows the d, q-axis equivalent circuit when taking into account the end effect[5], [6].
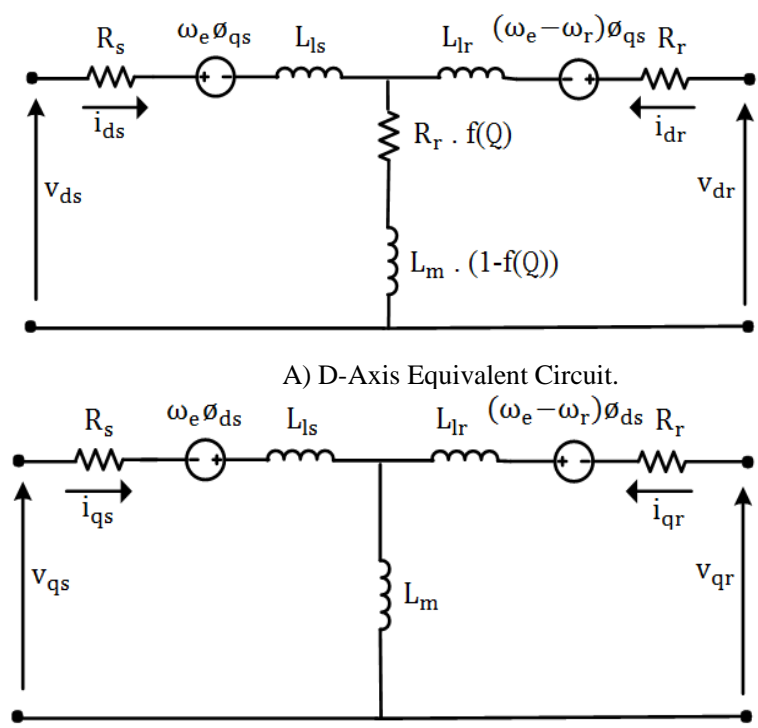

B) (Q-Axis) Equivalent Circuit.

Fig. 1: Equivalent Circuits of LIM with Consideration the End Effect.

The mathematical model of LIM can be expressed in a synchronous reference equations, where the equation primary and linor voltage equations are described as indifferential equations given below [3]-[6]:

$\mathrm{V}_{\mathrm{ds}}=\mathrm{R}_{\mathrm{s}} \mathrm{i}_{\mathrm{ds}}+\mathrm{R}_{\mathrm{r}} \mathrm{f}(\mathrm{Q})\left(\mathrm{i}_{\mathrm{ds}}+\mathrm{i}_{\mathrm{dr}}\right)+\mathrm{p} \lambda_{\mathrm{ds}}-\omega_{\mathrm{e}} \lambda_{\mathrm{qs}}$

$\mathrm{V}_{\mathrm{qs}}=\mathrm{R}_{\mathrm{s}} \mathrm{i}_{\mathrm{qs}}+\mathrm{p} \lambda_{\mathrm{qs}}+\omega_{\mathrm{e}} \lambda_{\mathrm{ds}}$

$\mathrm{V}_{\mathrm{dr}}=\mathrm{R}_{\mathrm{r}} \mathrm{i}_{\mathrm{dr}}+\mathrm{R}_{\mathrm{r}} \mathrm{f}(\mathrm{Q})\left(\mathrm{i}_{\mathrm{ds}}+\mathrm{i}_{\mathrm{dr}}\right)+\mathrm{p} \lambda_{\mathrm{dr}}-\omega_{\mathrm{sl}} \lambda_{\mathrm{qr}}$

$\mathrm{V}_{\mathrm{qr}}=\mathrm{R}_{\mathrm{r}} \mathrm{i}_{\mathrm{qr}}+\mathrm{p} \lambda_{\mathrm{qr}}+\omega_{\mathrm{sl}} \lambda_{\mathrm{dr}}$

The fluxes are described as:

$$
\begin{aligned}
& \lambda_{\mathrm{ds}}=\mathrm{L}_{\mathrm{ls}} \mathrm{i}_{\mathrm{ds}}+\mathrm{L}_{\mathrm{m}}(1-\mathrm{f}(\mathrm{Q}))\left(\mathrm{i}_{\mathrm{ds}}+\mathrm{i}_{\mathrm{dr}}\right) \\
& \lambda_{\mathrm{qs}}=\mathrm{L}_{\mathrm{ls}} \mathrm{i}_{\mathrm{qs}}+\mathrm{L}_{\mathrm{m}}\left(\mathrm{i}_{\mathrm{qs}}+\mathrm{i}_{\mathrm{qr}}\right) \\
& \lambda_{\mathrm{dr}}=\mathrm{L}_{\mathrm{lr}} \mathrm{i}_{\mathrm{d} r}+\mathrm{L}_{\mathrm{m}}(1-\mathrm{f}(\mathrm{Q}))\left(\mathrm{i}_{\mathrm{ds}}+\mathrm{i}_{\mathrm{dr}}\right) \\
& \lambda_{\mathrm{qr}}=\mathrm{L}_{\mathrm{lr}} \mathrm{i}_{\mathrm{qr}}+\mathrm{L}_{\mathrm{m}}\left(\mathrm{i}_{\mathrm{qs}}+\mathrm{i}_{\mathrm{qr}}\right)
\end{aligned}
$$

In the above equations, $\mathrm{V}_{\mathrm{ds}}, \mathrm{V}_{\mathrm{qs}}, \mathrm{V}_{\mathrm{dr}}, \mathrm{V}_{\mathrm{qr}}$, represent $\mathrm{d}$, q-axes primary and secondary estimated voltages; $\mathrm{i}_{\mathrm{ds}}, \mathrm{i}_{\mathrm{qs}}, \mathrm{i}_{\mathrm{dr}}, \mathrm{i}_{\mathrm{qr}} \mathrm{d}, \mathrm{q}$ axes primary and secondary estimated currents; $\lambda_{\mathrm{ds}}, \lambda_{\mathrm{qs}}, \lambda_{\mathrm{dr}}, \lambda_{\mathrm{qr}} \mathrm{d}, \mathrm{q}$ axes estimated flux linkage; $R_{s}, R_{r}$ resistance of the primary and secondary windings respectively, per phase; $\mathrm{L}_{\mathrm{s}}, \mathrm{L}_{\mathrm{r}}, \mathrm{L}_{\mathrm{m}}$ primary, secondary and mutual self-inductances respectively, per phase; $\mathrm{L}_{\mathrm{ls}}, \mathrm{L}_{\mathrm{lr}}$ leakage inductances for primary and secondary respectively, per phase; $\omega_{\mathrm{e}}, \omega_{\mathrm{r}}, \omega_{\mathrm{sl}}$ primary, secondary and slip electrical frequency respectively.

The $\mathrm{Q}$ factor is related by the length of primary, and by a specific degree in the end effects as a function of the primary, and to a specific degree in the end effects so as a function of the motor velocity as:

$$
\mathrm{Q}=\frac{D R_{r}}{\left(L_{m}+L_{l r}\right) v}
$$

It is noticeable the primary's length is depend inversely on the velocity, e.g. in a zero motor velocity, the primary's length can be considered infinite, and the end effects may be ignored. Therefore:

$f(Q)=\frac{1-e^{-Q}}{Q}$

When the motor velocity increases, the length of the primary decreases, i.e. increasing the end effects, which causes to decrease the magnetization current of the motor. This effect can be measured in terms of the magnetization inductance as:

$L_{m}^{\prime}=L_{m}(1-\mathrm{f}(\mathrm{Q}))$

The developed thrust force is given by[4]:

$F_{e}=\frac{3 \pi}{2 \tau_{p}} \cdot P \cdot\left(\lambda_{d r} i_{q s}-\lambda_{q r} i_{d s}\right)=M \cdot v^{\prime}+B \cdot v+F_{L}$

Where $\mathrm{Q}$ factor related to the length of primary; D primary length; $\mathrm{v}$ velocity $(\mathrm{m} / \mathrm{s}) ; \mathrm{P}$ is the number of pole pairs; $\tau_{p}$ pole pitch; $\mathrm{F}$ is the electromagnetic thrust force, $\mathrm{B}$ viscous friction and $\mathrm{M}$ total mass of the moving part.

The main principle of indirect field-oriented control of a LIM is to control the stator current by transferring the three-phase currents with using electrical position of the LIM to obtain a two phase current in d-q reference frame system. This leads to separation the variables of the flux and the torque and then control of the stator currents, direct-axis $i_{d s}$ and quadrature-axis $i_{q s}$ separately.

The indirect field-orientation method used the velocity feedback of the LIM to control the torque, where the velocity controller provide the reference quadrature-axis current $i_{q s}{ }^{*}$ for the current controller which compare with the feedback quadrature-axis current $i_{q s}$ to obtain the required voltage $v_{q}$ for the SVPWM inverter. While to control the rotor flux, the end effect factor $\mathrm{f}(\mathrm{Q})$ is used to obtain the reference direct-axis current $i_{d s}{ }^{*}$ for the current controller wich compare with the feedback direct-axis current $i_{d s}$ to obtain the required votage $v_{d}$ [5].

In IFOC, the secondary flux linkage axis of the LIM must be aligned with the d-axis and therefore:

$\lambda_{q r}=p \lambda_{q r}=0$

$\lambda_{d r}=\lambda_{r}=L_{m} i_{d s}$

Substituting equations (13) and (14) in equation (12), the thrust force equation can be represented as follows:

$F_{e}=\frac{3 \pi}{2 \tau_{p}} P \frac{L_{m}(1-f(Q))}{\left(L_{r}-L_{m} f(Q)\right)} \lambda_{d r}$

By combining equations (13) and (14) with equations (3) and (7), the slip (feed-forward slip) velocity can be obtained as follows: 
$v_{s l}=\frac{\tau_{p} \cdot L_{m}(1-f(Q)) \cdot i_{q s}{ }^{*}}{\pi \cdot\left(\frac{L_{r}}{R_{r}}-\frac{L_{m} f(\mathrm{Q})}{R_{r}}\right) \cdot \lambda_{d r}}$

While the electrical velocity as described as follows:

$v_{e}=v_{s l}+v_{r}$

The decoupling control method using two current controllers that utilized to provide the required control voltages to the inverter can be expressed as follows:

$V_{d s}{ }^{*}=($ current controller $)\left(i_{d s}{ }^{*}-i_{d s}\right)-\frac{\pi}{\tau_{p}} v_{e} L_{\sigma}(Q) i_{q s}{ }^{*}$

$V_{q s}{ }^{*}=($ current controller $)\left(i_{q s}{ }^{*}-i_{q s}\right)+\frac{\pi}{\tau_{p}} v_{e} L_{\sigma}(Q) i_{d s}{ }^{*}+$

$\frac{P . L_{m}}{L_{r}} \frac{\pi}{\tau_{p}} v_{r} \lambda_{d r}$

While the velocity controller can be represented as follows:

$\mathrm{S}\left(v_{r}{ }^{*}\right)=i_{q s}{ }^{*}=($ Speed Controller $)\left(v_{r}{ }^{*}-v_{r}\right)$

Where $i_{q s}{ }^{*}, i_{d s}{ }^{*}$ and $v_{r}{ }^{*}$ are the reference values of the d-q axis of the secondary currents and velocity, respectively; $L_{\sigma}(Q)$ is the total leakage inductance. It can be expressed as follow:

$L_{\sigma}{ }^{\prime}=L_{\sigma}(Q)=L_{s}-L_{m} f(Q)-\frac{\left(L_{m}(1-f(Q))\right)^{2}}{L_{r}-L_{m} f(Q)}$

\subsection{Recurrent wavelet neural network (RWNN)}

Wavelet neural networks (WNN) is a sophisticated type of neura networks by adding wavelets as a activation functions in the hidden layers of the neural networks. The merge of neural networks and wavelet theory has led to produce an efficient networks called WNNs. WNNs can be contains one or more inputs, with one hidden layer and one or more output. The hidden layer consists of neurons with wavelet activation functions instead of classical sigmoid activation functions. Where the weights of the network along with the translation and dilation of the wavelets function are optimized using some learning algorithm to get adaptive WNN. Wavelet neural networks (WNNs) can be categorized into feedforward (non-recurrent) and recurrent categories [7], [8].

The recurrent wavelet neural network (RWNN) is proposed in this paper to control the velocity of LIM. The RWNN is feedforward WNN with feedback connections as shown in Fig.2. The feedback connection may be totally for each layer in the network which is called fully feedback while the feedback from the output to the input network is called partially feedback. The RWNN network incorporates the ability of learning by neural networks from the system and the ability of decomposition by wavelet approach for the effective control of dynamic schemes. Moreover, it contains a number of delays samples in the input and output of the network. It was found in this work that, the Mexican hat wavelet is more useful as the wavelet function, which is given as follows:

$\psi(x)=\left(1-e^{2}\right) \exp ^{\frac{-e^{2}}{2}}$

Hence, the output for each layer can be computed as [8]:

$\psi_{N}=\psi\left(\frac{u_{N}-b_{N}}{a_{N}}\right)$

Where, e is the error of the system $a_{N}$ and $b_{N}$ are the dilation and the translation factors of the wavelets, respectively. The inputs to hidden layer for time, $\mathrm{n}$, can be indicated as:

$u_{N}(n)=e+\Delta e+\psi_{N}(n-1) * \emptyset_{N}+y\left(n-D_{0}\right) * r_{N}$

Where, $\emptyset_{N}$ is the weight of the output self-feedback loop. The output of the network is given as follow:
$y=\sum_{N=1}^{N} w_{N} \psi\left(\frac{u_{N}-b_{N}}{a_{N}}\right)$

where, $\Delta e$ is the change of error, $\mathrm{N}$ is the number of neuron in the hidden layer, $w_{N}$ is the output weight, $D_{0}$ is the number of delay for the output network, $r_{n}$ is the weight of the output feedback loop.

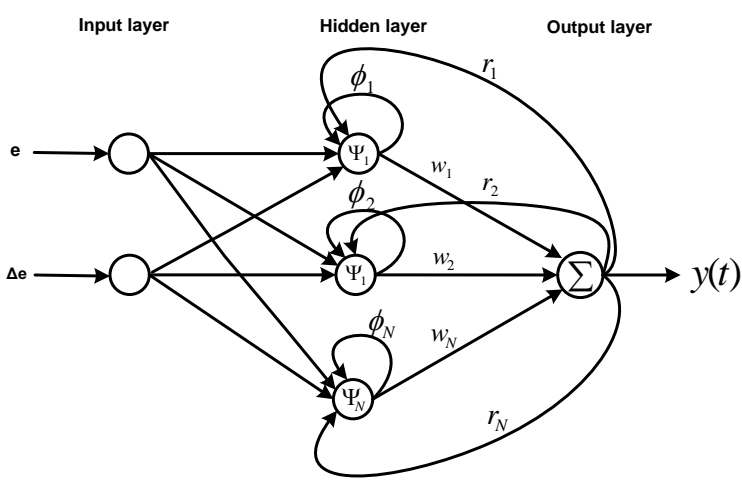

Fig.2: Wavelet Neural Network Structure Based on LIM Velocity Control.

\subsection{Particle swarm optimization technique}

Particle Swarm Optimization is one of the stochastic search techniques utilized to solve problems related with optimization. It is based on the intelligence swarms during their search on food. This algorithm has been developed to find the optimal solution in nonlinear systems and multi-dimensional systems according to the certain goal. In PSO algorithm, each individual solution is called a particle which fly in the swarm through a multidimensional search space[9]. Every particle is described by two vectors, velocity and position in the search space which have an initial value. Every particle changes its position with time according to its own expertise and that of neighbors.

The position of any particle is influenced by the best itself visited position i.e. its own expertise and the position of the perfect particle in its locality experience of adjoining particles. When the locality of a particle is the entire swarm, the perfect position in the locality is directed to as the global perfect position of the particle and the resulting algorithm is directed to as the global perfect position PSO. Where the perfect previous position (giving the minimum fitness value) of any particle is called local best position (lbest). The index of the best particle among all particles in the population is called global best position (gbest). When smaller locality are used, the algorithm is generally directed to as the lbest PSO. The execution of each particle is measured using a fitness function that varies depending on the problem of optimization.

For a multidimensional problem, the velocity and position of each particle in the swarm are updated by using the equations:

$\mathrm{v}_{\mathrm{i}}^{\mathrm{k}+1}=\mathrm{w} * \mathrm{v}_{\mathrm{i}}^{\mathrm{k}}+\mathrm{c}_{1} * \mathrm{R}_{1} *\left(\right.$ lbest $\left._{\mathrm{i}}-\mathrm{x}_{\mathrm{i}}^{\mathrm{k}}\right)+\mathrm{c}_{2} * \mathrm{R}_{1} *$

$\left(\right.$ gbest $\left._{i}-x_{i}^{k}\right)$

$x_{i}^{k+1}=x_{i}^{k}+v_{i}^{k+1}$

Where, $x_{i}^{k}, v_{i}^{k}$ are the instant position and speed of particle $i$ at iteration $\mathrm{k}$ respectively, $\mathrm{w}$ is the inertia weight, $\mathrm{c}_{1}$ and $\mathrm{c}_{2}$ are the acceleration constants and $R_{1}, R_{2}$ represent a random variables between 0 and 1 .

$\mathrm{w}=\mathrm{w}_{\max }-\frac{\left(\mathrm{w}_{\max }-\mathrm{w}_{\min }\right)}{\text { iter }_{\max }}$

$\mathrm{w}_{\max }$ and $\mathrm{w}_{\min }$ respectively are the maximum and minimum weights, iter is the current iteration time and iter max $_{\text {is }}$ the maximum number of iterations. In order to get better dynamic performance for the LIM, the fitness function should be minimize. 
Where the fitness function depends on the controller of the system. In this paper, a multi-objective fitness function is utilized to find the optimal solution with a minimum velocity error based on the minimum Integral of Squared Error (ISE) criterion and minimum overshoot $\left(\mathrm{M}_{\mathrm{o}}\right)$ criterion as follow[9-12]:

Fitness function $=\min ($ ISE $)+\min \left(M_{o}\right)$

Where

$$
\begin{aligned}
& \text { ISE }=\int e(t)^{2} d t \\
& M_{o}=v_{\text {max }}-v_{\text {ref }} \\
& e(t)=v-v_{\text {ref }}
\end{aligned}
$$

Where $\mathrm{v}$ and $\mathrm{v}_{\text {ref }}$ is the actual and desired velocity of LIM, respectively. According to the above, the PSO algorithm can be given in a flow chart as shown in Fig.3.

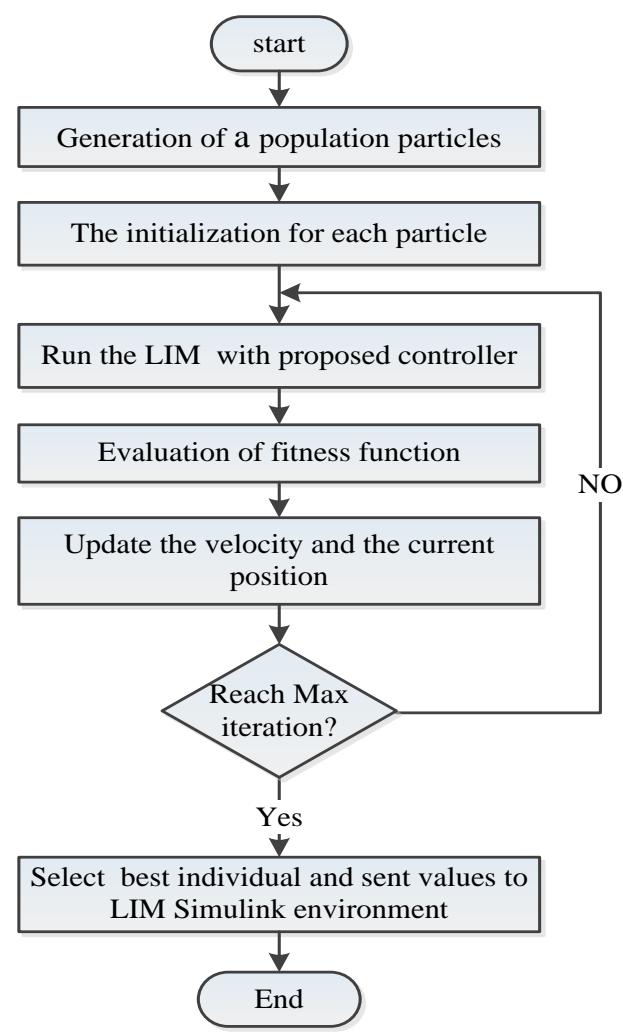

Fig. 3: General Flow Chart of PSO Based on LIM Velocity Control.

\section{Velocity control of LIM using optimal RWNN-PID controller}

The recurrent wavelet neural network controller with PSO algorithm based on indirect oriented control (IFOC) is proposed to control the velocity of LIM .The overall drive system of LIM with the proposed controller is shown in Fig.4. It consist of three phase LIM considering end effects is controlled by three-phase voltage source inverter used to provide the required voltage and the in verter receives the control signals from the proposed controller. A SVPWM technique is used to control the three phase inverter . The proposed control system consists of two schemes velocity controller and current controller. The velocity controller is used to control the velocity of LIM, which consist of RWNN with PID controller in parallel to produce modified controller called RWNN-PID controller which utilized to give the required dynamic action to achieve the required velocity with good performance.
While the current controller is used to control the flux of the LIM using RWNN controller to give the required voltage control to three phase inverter. Where the current controller based on IFOC, consist of two loop. The first loop utilized to control the rotor flux magnitude using the direct axis current $i_{\mathrm{ds}}$, while the second loop used the quadrature axis current $i_{\text {qs }}$ to control the generated torque and $\omega$.

The proposed RWNN contains of three layers, with two inputs in the input layer; the velocity error and the change of this error. The hidden layer has five neurons with Mexican-hat wavelet function and one output layer which feedback connection from the output for each layer. The feedback is used here called "Fully feedback". A PSO algorithm is utilized for learning the parameters of the proposed RWNN-PID controller and find the optimal values. According to learning the PSO algorithm, the parameters of PSO

\begin{tabular}{|c|c|}
\hline PSO_Parameter & Value \\
\hline Swarm Size & 50 \\
\hline Maximum iteration number & 60 \\
\hline Dimension of problem & 15 \\
\hline Acceleration constant $c_{1}, c_{2}$ & 2 \\
\hline $\mathrm{W}_{\max }$ & 0.9 \\
\hline $\mathrm{W}_{\min }$ & 0.3 \\
\hline
\end{tabular}
algorithm was found as in Table (1).

Table 1: PSO Contents

\section{Simulation results}

The Simulink model of the LIM drive system with the proposed controller is implemented in Matlab/Simulink software package as shown in Fig.5. It has been built according to the previous mathematical modeling equations given in section II.

Figure 6 shows the Simulink model of the proposed RWNN-PID controller. The parameters of LIM are given in Table (2).

Table 2: Parameters of LIM

\begin{tabular}{llll}
\hline Parameters & Value & Parameters & Value \\
\hline $\mathrm{R}_{\mathrm{S}}(\Omega)$ & 13.2 & $\tau_{\mathrm{p}}(\mathrm{m})$ & 0.0465 \\
$\mathrm{R}_{\mathrm{r}}(\Omega)$ & 11.78 & $\mathrm{M}(\mathrm{Kg})$ & 4.775 \\
$\mathrm{~L}_{\mathrm{S}}(\mathrm{H})$ & 0.42 & $\mathrm{P}$ & 4 \\
$\mathrm{~L}_{\mathrm{r}}(\mathrm{H})$ & 0.42 & $\mathrm{~B}(\mathrm{Kg} / \mathrm{s})$ & 53 \\
$\mathrm{~L}_{\mathrm{M}}(\mathrm{H})$ & 0.4 & $\lambda_{\mathrm{r}}(\mathrm{Wb})$ & 0.056 \\
\hline
\end{tabular}

To validate the proposed controller to control the velocity of LIM, several tests have been implemented under different operating conditions such as velocity response during load and no load, sudden step change in reference velocity, step change in the load. The linear velocity response is fixed at the reference velocity $4(\mathrm{~m} / \mathrm{sec})$ with no load condition, and a sudden thrust of $200 \mathrm{~N}$ is added at $\mathrm{t}=0.5 \mathrm{sec}$ as shown in Fig.(7). The developed thrust during no load and load condition is shown in Fig.(8). Figures (9) and (10) show the d-q components of primary current at no load and load condition. Figures (11) and (12) show the d-q components of secondary current at no load and load condition. The $F(Q)$ function for the same starting and loading conditions is shown in Fig.(13).

Figure (14) shows the step change in the developed thrust load with fixed in the reference velocity $4(\mathrm{~m} / \mathrm{sec})$. Where the load is changed from no load at starting and a sudden thrust of $100 \mathrm{~N}$ is added at $\mathrm{t}=0.3 \mathrm{sec}$ and increases $100 \mathrm{~N}$ every $0.2 \mathrm{sec}$. Figure (15) shows the linear velocity response during the step change in the thrust. Figure(16) shows the comparison between the linear velocity response with RWNN-PID controller and with PID controller. The variation of secondary resistance and magnetizing inductance will occur due to the continuous operation at high temperature and changes the thrust load under unsuitable conditions. 


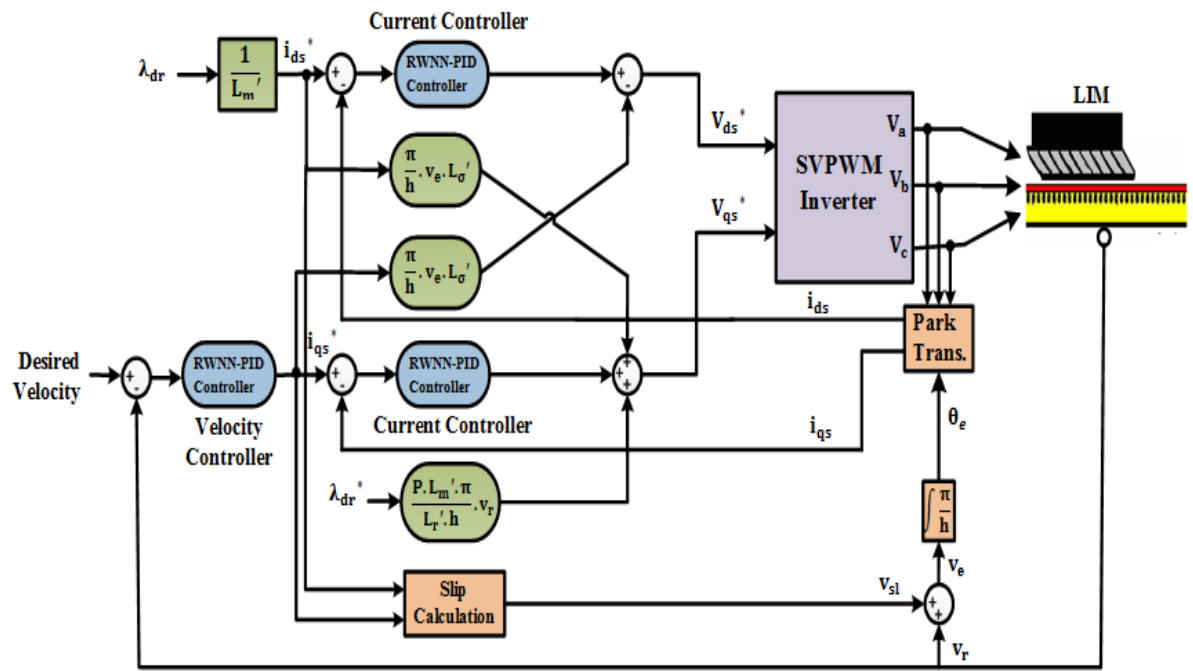

Fig. 4: Block Diagram of LIM with the Proposed Controller Based on IFOC.

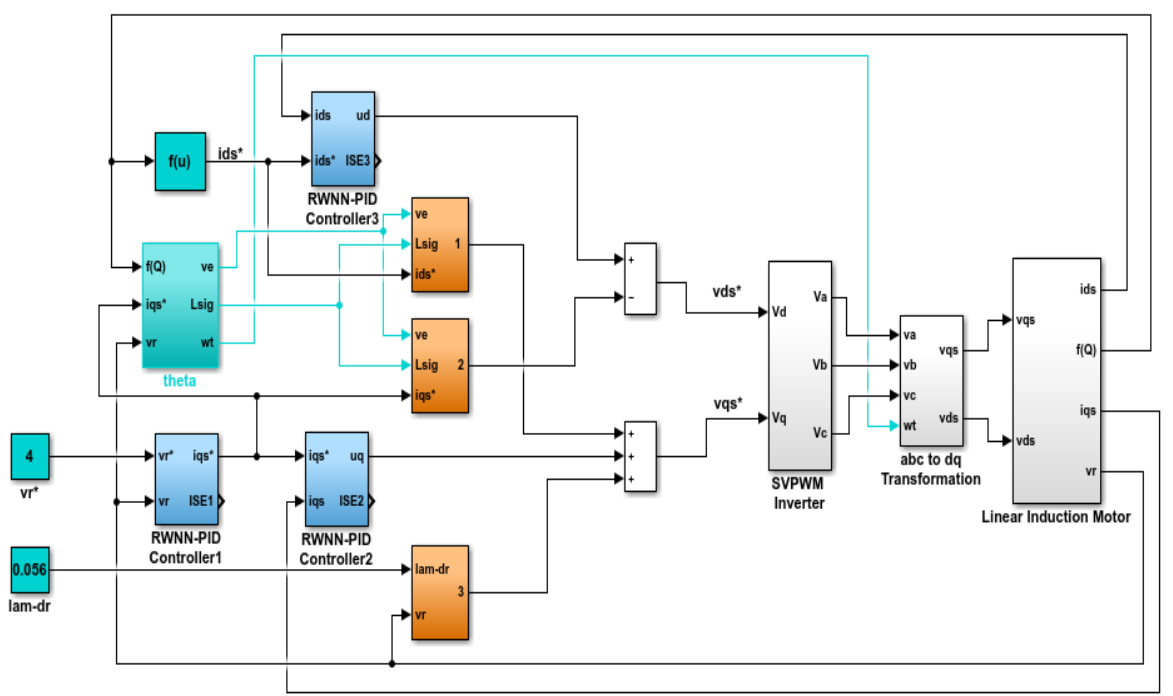

Fig. 5: The Simulink Model of LIM Drive System with the Proposed Controller Based on IFOC.

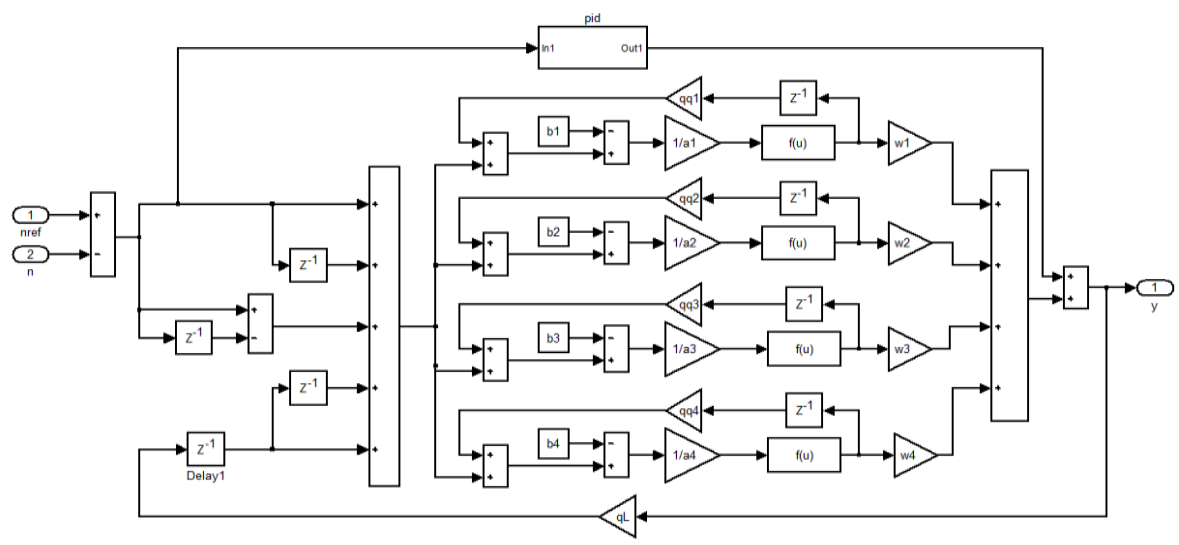

Fig. 6: The Simulink Model of the Proposed RWNN-PID Controller with PSO Algorithm.

In this paper, the proposed controller is tested with an increasing value of the secondary resistance and magnetizing inductance $\left(R_{r}=1.5 R_{r n}, L_{m}=1.2 L_{m n}\right)$ of the LIM drive system to get more robust controller and less sensitive with the uncertainty of the motor parameters compare with conventional controllers.
Figure(17) shows the effect of varying the resistance and magnetizing inductance compared with normal $\mathrm{R}_{\mathrm{r}}$ and $\mathrm{L}_{\mathrm{m}}$ on the velocity response. The simulation results show that the proposed RWNN with PID controller based on IFOC offers more accurate dynamic response and better performance for to control the velocity of LIM drive system compare with the conventional methods. 


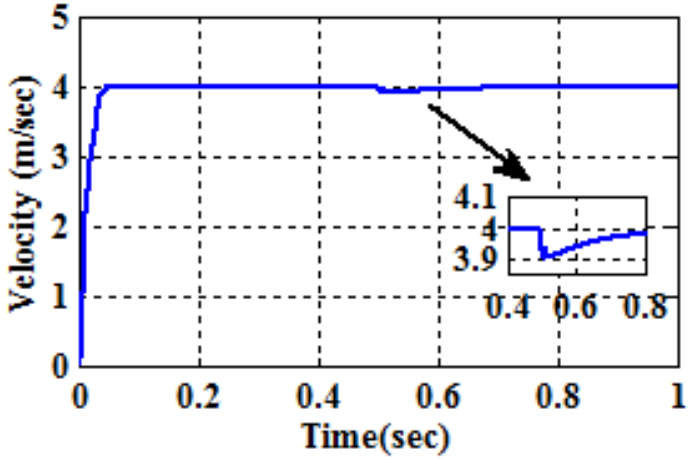

Fig. 7: The Velocity Response under All Conditions.

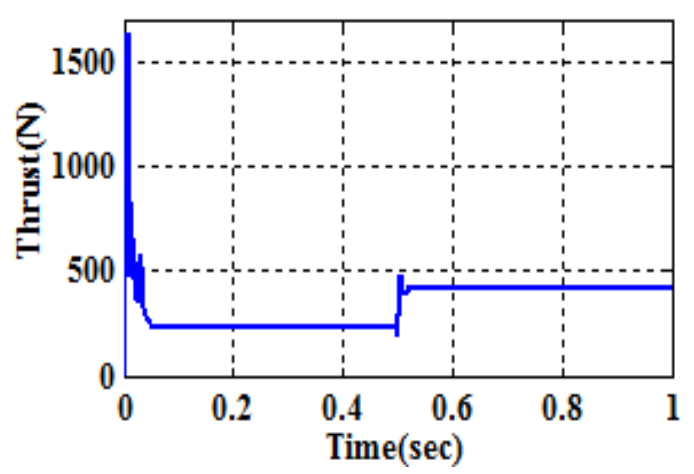

Fig. 8: Developed Thrust Force of the LIM.

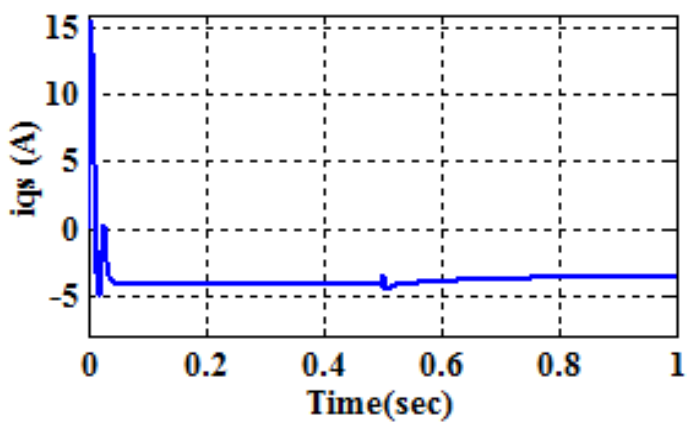

Fig. 9: Q-Axis Component for Primary Current at All Conditions.

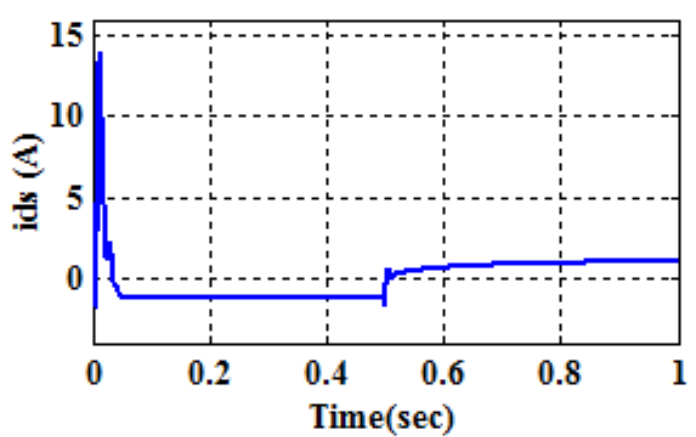

Fig. 10: D-Axis Component for Primary Current at All Conditions

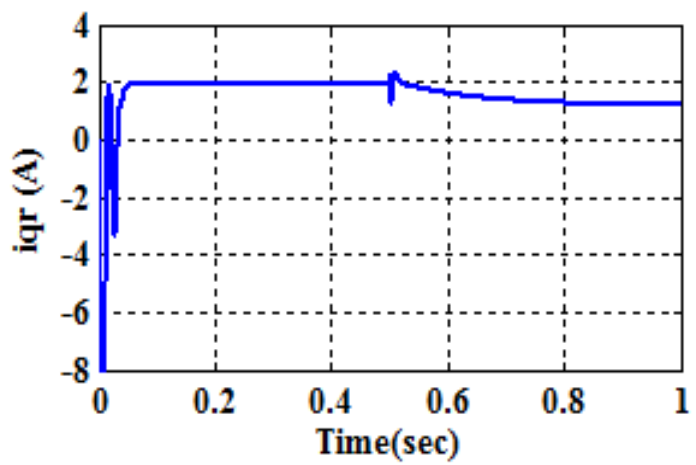

Fig. 11: Q-Axis Component for Secondary Current at All Conditions.

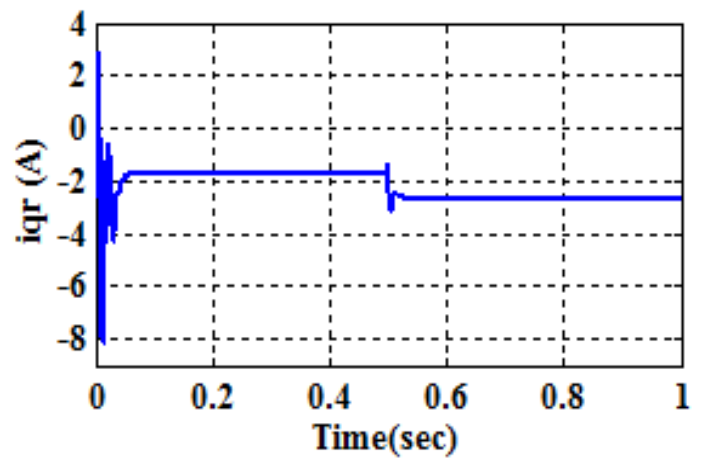

Fig. 12: D-Axis Component for Secondary Current at All Conditions.

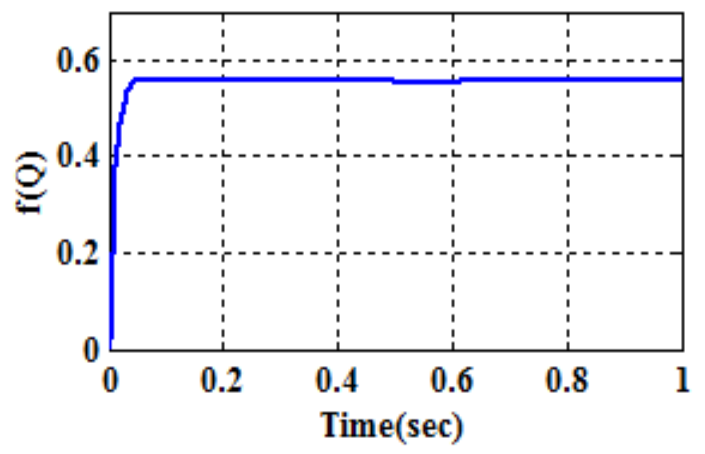

Fig. 13: The $F(Q)$ Function.

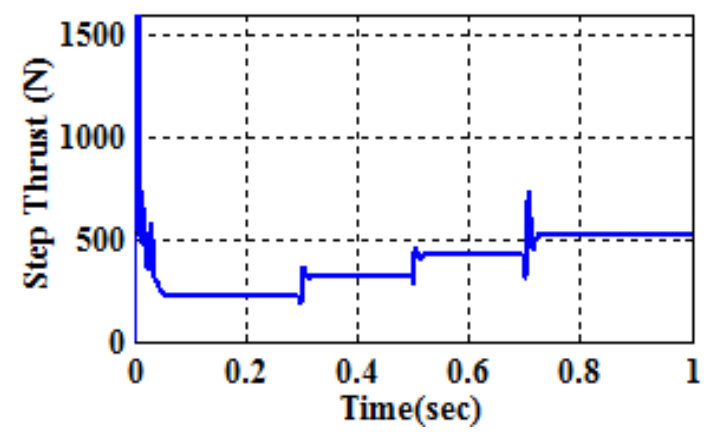

Fig. 14: The Step Change in the Developed Thrust.

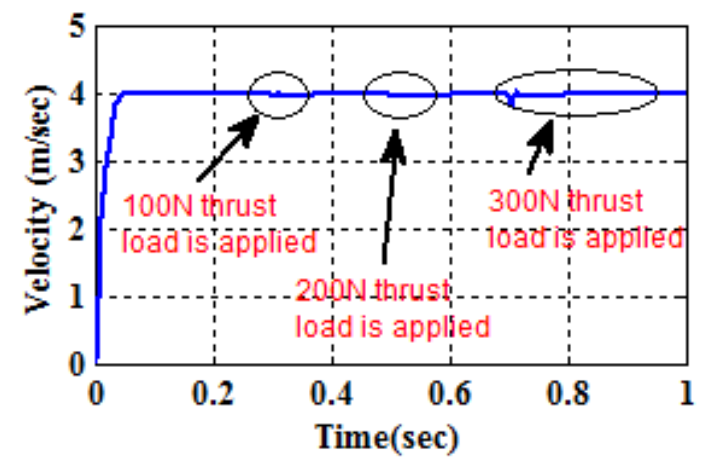

Fig. 15: The Linear Velocity Response during the Step Change in the Thrust.

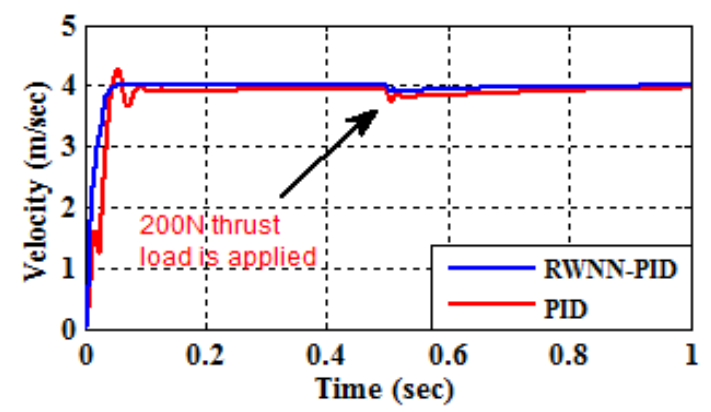

Fig. 16: The Linear Velocity Response with RWNN-PID and PIDController. 


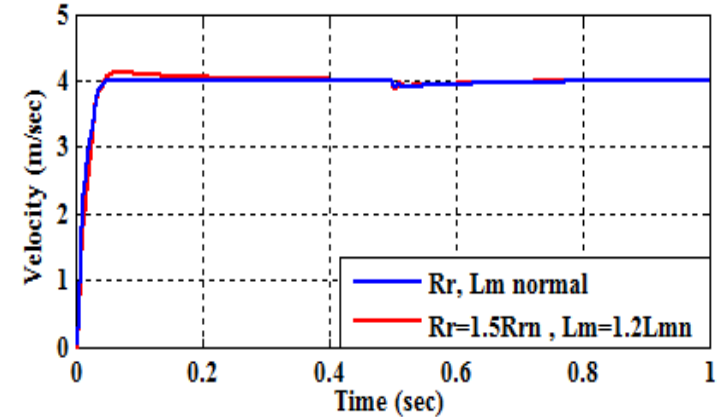

Fig. 17: Effect of Varying the Resistance and Magnetizing Inductance Compared with Normal $\mathrm{R}_{\mathrm{R}}$ and $\mathrm{L}_{\mathrm{M}}$ on the Velocity Response.

\section{Conclusion}

This paper presents modified controller called RWNN-PID controller to control the velocity of LIM based on IFOC strategy. Particle swarm optimization algorithm is applied for tuning all the parameters of RWNN and PID controllers. The velocity response shows improvement in, rising time, settling time, overshoot and steady state error. The drive provides a flexible and robust. It provides a flexible and robust due to effect of changes in motor parameters.

\section{References}

[1] Jean Thomas and Anders Hansson, "Speed Tracking of a Linear Induction Motor-Enumerative Nonlinear Model Predictive Control", 2013, IEEE Transactions on Control Systems Technology, Vol.21, No.5, 2013, pp. 1956-1962. https://doi.org/10.1109/TCST.2012.2217745.

[2] Kou-Cheng Hsu and Hsin-Han Chiang, "Optimized Adaptive Sliding-mode Position Control System for Linear Induction Motor Drive", IEEE, $201310^{\text {th }}$ International Conference on Networking, Sensing and Control (ICNSC), Evry, France, 10-12 April 2013 , pp. 355-360

[3] Essam E. M. Mohamed, Mahmoud A. Sayed and Tarek Hassan Mohamed, " Sliding Mode Control of Linear Induction Motors Using Space Vector Controlled Inverter", IEEE, 2013 International Conference on Renewable Energy Research and Applications, Madrid, Spain, 20-23 October 2013, pp.650-655 https://doi.org/10.1109/ICRERA.2013.6749835.

[4] Wang Yuhua and Guo Kang, "Speed and Rotator Magnetic Flux Close Loop vector control system for The Linear Induction Motor Based on Neuron adaptive Controller", IEEE, International Conference on Management and Service Science, Sept. 2009. https://doi.org/10.1109/ICMSS.2009.5303046.

[5] A. Boucheta, I. K. Bousserhane, A. Hazzab ,B. Mazari and M. K Fellah, "Linear Induction Motor Control Using Sliding Mode Considering the End Effects", IEEE, 2009 6th International MultiConference on Systems, Signals and Devices, 19 May 2009, pp.1-6.

[6] Pegah Hamedani and Abbas Shoulaie, "Indirect Field Oriented Control of Linear Induction Motors Considering The End Effects Supplied from a Cascaded H-Bridge Inverter with Multiband Hystersis Modulation", IEEE, 4th Power Electronics, Drive Systems \& Technologies Conference (PEDSTC2013), Feb 13-14, 2013, Tehran, Iran, pp.13-19.

[7] Adel A. Obed and Ameer L. Saleh, "Speed Control of BLDC Motor Based on Recurrent Wavelet Neural Network", Iraq J. Electrical and Electronic Engineering, Vol.10 No.2, 2014, pp.118-129.

[8] Rong-Jong Wai and Han-Hsiang Chang, "Backstepping Wavelet Neural Network Control forIndirect Field-Oriented Induction Motor Drive", IEEE Transactions on Neural Networks, Vol. 15, No. 2, March 2004, pp. 367-382. https://doi.org/10.1109/TNN.2004.824411.

[9] J.J. Jamian, M.W. Mustafa and H. Mokhlis, "Implimentation of Evolutionary Particle Swarm Optimization in Distributed Generation Sizing", International Journal of Electrical and Computer Engineering (IJECE), Vol. 2, No. 1, February 2012, pp. 137-146.

[10] Hossein Shahinzadeh, Sayed Mohsen Nasr-Azadani and Nazereh Jannesari, "Applications of Particle Swarm Optimization Algorithm to Solving the Economic Load Dispatch of Units in Power Systems with Valve-Point Effects", International Journal of Electrical and
Computer Engineering (IJECE), Vol. 4, No. 6, December 2014, pp 858-867. https://doi.org/10.11591/ijece.v4i6.6720.

[11] Ameer L. Saleh, Maab A. Hussain and Sahar M.Klim, "Optimal Trajectory Tracking Control for a Wheeled Mobile Robot Using Fractional Order PID Controller", Journal of University of Babylon, Engineering Sciences, Vol.26, No.4, 2018, pp. 292-306. https://doi.org/10.29196/jubes.v26i4.1087.

[12] Mohamed Elhedi Hmidi, Ines Ben Salem, Lilia El Amraoui, "Design and simulation of a 2DOF PID controller based on particle swarm optimization algorithms for a thermal phase of hybrid vehicle", International Journal of Engineering \& Technology, Vol.7, No.2, 2018, pp. 506-511. 